\title{
OD or Not an OD - a Case Study Analysis of Organizational Development Practices in Government Sector Organizations in Pakistan
}

\author{
Farooq-E-Azam Cheema \\ Dean Faculty of Management Science at Institute of Business \& Technology (Biztek) \\ Nadeem A. Syed \\ Associate Professor at FAST Business School, National University Karachi Campus
}

\begin{abstract}
Purpose-Purpose of this case study and its analysis is to highlight the structural and functional changes in the government sector organizations Pakistan undertaken under the name of organization development. Whereas, in fact, there is a great mismatch between the theory and practice of organizational development as far as the government sector organizations in developing countries like Pakistan go.

Methodology-The study is based on comprehensive literature reviewed critically and the diverse factors affecting these two activities as tools of employee development identified including their pre-requisites and possible barriers in the way of their introduction and application.

Findings-In theory and practice both, Organizational development is aimed at improving an organization's performance and individual development of its employees. It focuses on the health of entire organization rather than a particular group or certain individuals. This process requires the organization be viewed as a consistent system composed of many subsystems, the human resources being the most important one. Involvement of the people in the process of organizational development is hall mark of this process.

Practical Implications-Findings of the case study have professional implications for the OD practitioners. They, perhaps, may not follow the OD good practices in certain OD interventions that are context specific like team-building, participatory management style, MBO, job enrichment, reward administration etc. similarly, nor can they suggest long term OD interventions keeping in view the ad hoc natured culture and system of such departments.
\end{abstract}

Keywords : Organizational development, government organizations, OD good practices oc practices

\section{Jel classification :}

\footnotetext{
* The material presented by the author does not necessarily portray the viewpoint of the editors and the management of the Institute of Business \& Technology (Biztek) or FAST Business School, National University Karachi.

* Farooq-E-Azam Cheema: dr.cheema@biztekian.com

* Nadeem A. Syed : nadeem.syed@nu.edu..pk

(C) JMSS is published by the Institute of Business and Technology (Biztek). Main Ibrahim Hydri Road, Korangi Creek, Karachi-75190, Pakistan.
} 
OD or Not an OD - a Case Study Analysis of Organizational Development Practices in Government Sector Organizations in Pakistan

\section{INTRODUCTION}

Federal Board of Revenue (previously called Central Board of Revenue when this case in fact took place, hence, hereinafter to be called as CBR) is Federal Government revenue collecting body in Pakistan with its head office in Islamabad that collects revenue on account of the custom duty, sales tax, income tax and central excise through its field formations all over the country. It is headed by the Chairman directly assisted by seven Members heading its different sub-divisions. This body, being a 'bread winning entity' for the country, has been under the spotlight of the successive governments under the pressure of World Bank (Bainbridge 1997) for quite some time. Since 1988 onward it had never been able to achieve its annual revenue target, hence a source of concern for those at the helm of the affairs. Main cause of concern had remained revenue leakage caused by the rampant corruption all along the hierarchy.

\section{FIRST CHANGE ATTEMPT: PROCEDURAL CHANGE IN PRICE REPORTING SYSTEM}

Through a political decision the political government, contracted two Swiss companies $\mathrm{M} / \mathrm{s}$ Cotecna and M/s SGS in 1995 against heavy fees for reporting the price of the goods being imported in Pakistan directly to the customs staff. The aim was to break the exporterimporter-custom official collusion through eliminating their control over the price ascertaining mechanism replacing it with direct information by the contractors about value of the goods that they were supposed to collect through the independent sources in the country of export.

The change by virtue of volume was meagre but, by virtue of the gravity it was a sweeping change since the customs staff from top to bottom had lost their nuisance value inherited in ascertaining of the price of the import goods.

The procedural change introduced had following characteristics:

1. The change was introduced through an office order without any change agent.

2. CBR top management was not taken into confidence (French \& Bell et. al 1999). Rather an administrative order was issued by the Ministry of Finance and the CBR management was instructed to make SOPs accordingly.

3. Since the change lacked senior CBR management support (Beckhard \& Harris 1987, James 1999) there was no one to manage that change (Cumming \& Rouse et. al 1989), rather the employees from top to bottom left no stone unturned to foil it through tacit and passive resistance (Johns et. al 1996).

4. Change was merely procedural without needed work on the concomitant behavioural improvement (James 1999).

5. Targeted procedural change was a partial change (French \& Bell et. al 1999) in isolation from the predominant import related functions and procedures that had symbiosis among themselves.

6. It was an ad hoc based attempt to reining in the officialdom and plugging the' revenue leakage rather than changing the culture or creating effectiveness (Cummings $\&$ Huse et. al 1989) of the department in the long run.

The change was practised for one year and collapsed badly, abandoned by the government itself. Local staff of the contractor companies was also got sucked in the culture of the department and indulged in corrupt practices. So, larger revenue leakage was recorded compared to the earlier. The contract led to a notorious political scandal as well. 


\section{SECOND CHANGE ATTEMPT: IMPLEMENTING THE WORLD BANK REFORMS AGENDA}

In 2002, the World Bank sanctioned a grant for revenue collection automation project as part of its tax reforms agenda. Taking lesson from the history, the then Finance Minister decided to get the change attempt internalised in the CBR. So, he promoted a senior bureaucrat from within as Chairman CBR and entrusted him the change agenda. The new chairman hired a senior HR person with a vast experience of HR field in the multinational organizations _ as a change agent (Hunsaker 1982) _ and delegated him implementation of the reforms agenda. The pilot project was launched at Karachi port.

\subsection{Contextual features}

Though the change was once again externally initiated (Bainbridge 1997) but this time it was internalised by the top management and it assumed the responsibility for its execution. Change agent was internal (Hunsaker 1982) and had full support of the top management (Beckhard \& Harris 1987; James 1999). In clear deviation from the past attempts, this time the field staff did not have tacit approval of the senior field management for resisting the change (Lipton 1996). Rather, the heads of the field formations were given the special task to communicate the staff inevitability of automation owing to global pressure (Greenhause et. al 1994). That really worked, and the staff got intrinsically prepared for the change (Lipton 1996) before the work towards automation actually started.

\subsection{Interventions introduced by the change agent}

Outstanding feature of this change attempt was that instead of moving straightaway to the project, unlike the past, the Member (HR), the change agent, did not take the reforms agenda in isolation from the people (James 1999). Rather, he focussed on mobilizing the operating staff and creating ripples in the rigid bureaucratic culture ipso facto resistant to change (Schein 1984). So, he started his work from people related changes given below (Burke 1994) targeting at their well being (Beer \& Walton 1987). Work towards project was initiated far later. By that time the staff had restored its confidence in the CBR management regarding their future job security (Lipton 1996).

1. Reward system was made more viable at the group as well as the individual level (Cummings \& Worley 2001). 10\% of the revenue collected over and above the target was announced to be distributed among the employees proportionate to their base pay.

2. First time in the CBR's history, departmental promotion examination was introduced replacing the old seniority based promotion system for lower level staff. This kicked off the concept of the career management and development (Cummings et. al. 1989) in the department.

3. Archaic and altogether subjective performance appraisal system based on annual confidential report (ACR) practice (McCourt \& Eldridge 2003) was replaced with biennial interview based, and more objective performance appraisal (Ibid).

4. Before lodging the import processing automation project, general staff meetings were held at Custom House Karachi, first one of its own nature, attended by the Chairman CBR and the Member (HR) wherein fears of the employees were alleviated (Lipton 1996) and their commitment was sought.

5. Instead of issuing the posting orders as in the past, open choice was offered to the customhouse employees to join the automation pilot project. The volunteers were given proper training before their posting.

The project proved a success but temporarily. In two decades, it was the first time that the Collectorate of Customs Karachi achieved its target in the year 2003-04, but the revenue dropped again the next financial year. The member HR left the organization that year terminating his OD program halfway down, the officialdom relapsed to old habits. 
OD or Not an OD - a Case Study Analysis of Organizational Development Practices in Government Sector Organizations in Pakistan

\section{ANALYSIS OF THE ISSUES INVOLVED}

OD is more than reaching into the 'kit bag' and pulling out an intervention or two (French et. al 1999). Rather it involves, inter alia, systematic evaluation of the contextual factors, issues, and dynamics of the situation (Cummings et. al 2005). Following conclusions drawn from the case study of the change attempts in the CBR constitute the issues that have professional implications for the OD practitioners who have to keep them in mind while attempting OD interventions in the government departments in the developing countries like Pakistan. Any one or more of these contextual issues can pose threat to the effectiveness of the OD intervention if initiated without taking them into consideration.

\subsection{Bureaucratic culture is deep-seated, rigid and resistant to change}

The change brought about in the second attempt was not a deep change rather was a fistorder (French et. al 1999) or transactional change (Burke \& Litwin 1992), hence not durable. The reason of its shallowness and its poor effectiveness in the result was that it emanated from the change in the organizational climate (Ibid) superficially rather than through the change in the deep-rooted organizational culture (ibid). Organizational climate is constituted by the people's perceptions and attitudes about the organization (French et. al 1999), its systems, structure, and managerial behaviour (Burke 1994), and has a cause and effect relation with the psychological and organizational variables like motivation and performance (Ibid). It is synthetic and malleable and is easy to change (Burke \& Litwin 1992).

This change in the organizational climate was result of the short-term reciprocity (Burke 1994) between the management and the employees initiated by the former through improved communication, modification in the reward system (Burke et. al 1994) and managerial practices (French et. al 1999) and certain career development measures as mentioned in the case above. This changed climate improved the motivational level of the employees and, in turn, the organizational performance (Burke 1994), but only short lived. But as soon as the climate of reciprocity disappeared the officialdom reverted to olden habits.

Second-order (French et. al 1999) or transformational change (Burke \& Litwin 1992), which is deep-rooted and more genuine one (Burke 1994), could be brought about through changes in the deep-seated culture only (Burke \& Litwin 1992), which this change attempt could not bring about.

In fact, it was not possible to change the culture of the old bureaucratic establishment with in-built rigidity, consistency and control (Bainbridge 1998) revolutionarily nor it will ever be possible to do so in the future as well if attempted in isolation of the deep-rooted economic, social (Schein 1984), and bureaucratic factors that constitute its basis.

\subsection{Poor degree of involvement of the people}

Involvement of the people during the second change attempt was a clear defiance from the bureaucratic norms. Bureaucratic disposition may accept emphasis of the OD on the human resources, but to a limited level. Humanistic and optimistic approach of the OD to the people which proclaims treating the people with respect and dignity (French et. al 1999) and which draws upbeat account of the human nature in matters of the improvement, growth and self-actualization (Rees et. al 2002) in terms of the Theory Y (McGregor 1968), is extraneous to the bureaucratic organizations in the countries like Pakistan.

Instead the changes are introduced through the office orders and their implementation is taken for granted as a matter of duty. The officials belonging to the tax or police departments are particularly taken in terms of the Theory X (McGregor 1960) by the government in Pakistan, the concept on which the traditional bureaucratic organization 
has rested (Chin et. al 1976). Taking them incurable and fait accompli (Robinson 2002), they are used to be bypassed altogether in any change attempt initiated by the governments and solution is generally sought in bridling them indirectly through procedural changes.

This lack of involvement of the people in the attempted change impinged upon another basic principle of the OD: 'the whole system approach to the change'; that sees organization holistically (ODC News et. al. Dec. 1996) and includes individuals, teams and other organization units rather than concentrating on any one to the exclusion of the other(s) (Blake \& Mount 1969).

\subsection{Quick fix tendency rather than long-term planned change}

The quick-fixes (Kilmann 1989) with rapid though short-term results in a cookbook fashion (Beckhard 1969) are more cherished by the bureaucracies rather than the real health of the organization envisaged through the long-term planned changes (ibid). Such short-term changes are generally procedural lacking any concomitant behavioural improvements (Beckhard 1969, James 1999).

This tendency of the bureaucratic organizations can doom any OD intervention pertaining to improving the organizational effectiveness in the long-run (Warrick 1984; Hall 1977; Cummings \& Worley 2001) that OD brings about through developing the renewing capacity of the organizations (Beer 1980) and enabling them to solve their own problems through equipping their employees with requisite knowledge and skill. This notion of the OD reflects normative-re-educative strategy of change (Chin et. al. 1976) that implies improving the problem solving capabilities of a system through releasing and fostering growth in the persons.

Half done change attempts in a bid to correct the decades old rigidly driven bureaucratic organization without removing it from the government umbrella is characteristic example of this quick-fix tendency. The successive governments have remained unable to comprehend the cardinal fact that corruption, allegedly the root-cause of the issue, is prevalent not only in the CBR or other public sector organizations in Pakistan alone rather it is rampant across the developing countries in general having its roots in social, cultural, psychological and economic dimensions and cannot be addressed in isolation from them. So any contrivance/intervention to tackle it in isolation from the context (French et. al 1999) will be tantamount to treating the symptoms rather than the cause itself.

\subsection{Bureaucracy offers passive resistance to every change attempt that threatens their vested interests}

In the government sector of Pakistan majority of the changes are government initiated (Cook et. al 2005), hence government-bureaucracy relations are crucial in the matters of OD in the government departments. Here, professional bureaucracy is mighty (Blau 1980), and no external initiative or intervention can succeed in the departments without their consent and willingness. They, though, do not oppose the political government overtly but can hamstring any external move through tacit resistance (Lipton 1996) in pretext of the rules and regulations as they did during the first change attempt in the case under reference. So the political allegiance to the government which is not uniform among the bureaucrats has a lot of impact over the fate of the OD intervention(s) introduced.

Related to the above is the internal politics and divergence of interests among the bureaucrats. Those whose power is being threatened by the change intervention resist to it and those who are gaining power will be pushing it. So the OD consultant has to prepare an 'influence map' (Cummings et. al, 2005) before introducing the intervention. 
OD or Not an OD - a Case Study Analysis of Organizational Development Practices in Government Sector Organizations in Pakistan

\subsection{Bureaucratic system itself is resistant to change}

It is difficult to penetrate the rules and regulation laden bureaucratic system (LeBoeuf, 1985). These rules and regulations that are taken more as ends by themselves by the bureaucracy than the means (ibid) can cripple any OD intervention how much sophisticated it may be. Though the bureaucrats frequently take veneer of these rules and regulations to resist the changes initiated by the government from the outside, they even themselves often seem helpless before the rigidity of these rules and regulations.

\section{CONCLUSION}

The basic philosophical differences between the assumptions and values of the OD and those of the bureaucratic government sector organizations particularly those in the developing countries like Pakistan makes them an inhospitable host of the OD (Senior 1997). This has professional implications for the OD practitioners. They have to take proper care before contemplating OD interventions like team-building, participatory management style, MBO, job enrichment, reward administration because they can doom to failure in these organizations. Nor they should prescribe certain long-run interventions in this ad hoc natured culture and system. This general precaution is in fact foreign to the spirit of the OD itself and makes its application to the government departments difficult and sensitive though not impossible (ibid).

\section{BIBLIOGRAPHY}

1. Alderfer, C. (1977) 'Organization Development' Annual Review of Psychology' 28

2. Argyris, C. (1970) Intervention Theory and Method, Addison-Wesley

3. Bainbridge, C. (1997), Designing for Change, John Willey \& Sons

4. Beckhard, R. (1969), Organization Development: strategies and models AddisonWesley

5. Beckhard, R \& Harris, R (1987) Organizational Transactions: Managing Complex Change, $2^{\text {nd }}$ ed. Addison-Wesley

6. Beer, M. (1980), Organization Change and Development, Goodyear Publishing

7. Beer, M. \& Walton, E. (1987), 'Organization Change and Development', Annual Review of Psychology Journal, 38

8. Blake, R. \& Mouton, J. (1969) Building a dynamic corporation through grid organization development, Addison-Wesley

9. Burke, W. (1994) Organization Development: A Process of Learning and Changing, Addison-Wesley Publishing Company

10. Burke, W. \& Litwin, G. (1992) 'A Causal Model of Organizational Performance and Change', Journal of Management 18(3)

11. Chin, R. and Benne, K. (1976) 'Genral Strategies for Effecting Changes in Human Systems', The Planning of Change, $3^{\text {rd }}$ ed. Holt, Rinehart and Winston

12. Cooke, B. \& Nmeterson, N. (2005) 'Consultancy: Managing the Consultancy Process Unit 5', Organization Development IDPM

13. Cummings, T and Huse, F (1989) Organization Development and Change, West Publishing Co.

14. Cummings, T \& Worley, C. (2001), Essentials of Organization Change and Development, Thomson Publishing

15. Cummings, T \& Worley, C. (2005), Organization Development and Change, Thomson Publishing

16. Frankle, M. (1987) Values and Ethics in Organization and Human System Development: An Annotated Bibliography, AAAS Publication

17. French, W. \& Bell, C. (1999) Organization Development: Behavioral Science Interventions for Organization Improvement, $6^{\text {th }}$ ed. Prentice Hall

18. Gellermann, W., Frankel, M. \& Ladenson, R (1990) Values and Ethics in Organization and Human System Development: Responding to Dilemmas in Professional Life, 
Jossey-Bass George, M. and Jones, R. (1998), Understanding and Managing Organizational Behavior, Addison Wesley Publishers

19. Greenhaus, J. and Callinan, G. (1994), Career Management, Harcourt Brace College Publishers.

20. Hall, R. (1977), Organizations: Structure and Process, Prentice Hall

21. Hanna, P. D. (1988), Designing Organization for High Performance, Addison-Wesley Publishing Co.

22. Hanson, P. \& Lubin, B. (1995) Answers to Questions: Most frequently asked about Organization Development Sage Publication

23. Hunsaker, P. (1982) Strategies for change: The role of inside change agent, Personnel 59,5

24. James, R. (1999) Making it Personal_Leadership and Change in NGOs 'OD Debate' April, Olive, South Africa

25. Lawrence, P. \& Lorsch, J. (1969) Developing Organizations: Diagnosis and Action Addison-Wesley

26. LeBoeuf, M (1985) How to Motivate People, Garden City Press

27. Liddell, W. (1973) 'Marginality \& Integrative Decisions' Academy of Management Journal 16

28. Lipton, M. (1996) 'When clients resist change', Journal of Management Consulting, ABT/INFORM GLOBAL

29. Margulies, N. (1978) 'Perspectives on the Marginality of the Consultant's Role', The Cutting Edge: Current Theory and Practice in Organization Development, University Associates

30. Massarik, F. \& Pei-Carpenter, M. (2002) Organization Development and Consulting: Perspectives and Foundations Jossey-Bass

31. McCourt, W. \& Eldridge, D. (2003) Global Human Resource Management: Managing People in Developing and Transitional Countries, Edward Elgar Publishing

32. McGregor, D. (1961) 'The Human Side of Enterprise', The Planning of Change, $1^{\text {st }}$ ed. Holt, Rinehart and Winston.

33. Miles, M. (1979) 'Ethical issues in OD interventions', OD Practitioner, Volume 11 No. 3

34. ODC News Issue, December 1996 Issue 1, Organization Development Consultancy: Strengthening the Capacity of NGOs, INTRAC

35. Rees, C \& Sharifi, S. (2002) 'Organization Development: From Beliefs to Practice' Zagreb International Review of Economics \& Business, Special Conference Issue.

36. Robinson, J. (2002) Mastering Motivation, David Grant Publishing Ltd.

37. Schein, E. (1984) 'Culture as an Environmental Context' Journal of Occupational Behaviours John Wiley \& Sons

38. Schein, E. (1987) Process Consultation Volume II, Lessons for Managers and Consultants, Addison-Wesley

39. Senior, B. (1997) Organizational Change, Prentice Hall

40. Smith, S. \& Tranfield, S. (1991) Consultancy Skills Manual, Technical Communication

41. The International Organization Development Code of Ethics (December 1991, 22nd Revision) http://members.aol.com/odinst/ethics.htm, visited on 04-05-2006, 2.20 p.m

42. Warrick, D. (1984), 'Organization Development', Human Resource Management and Handbook, American Management Association

41. Ziller, R., Stark, B. \& Pruden, H. (1969) 'Marginality and Integrative Management Position' Academy of Management Journal 12 